NBER WORKING PAPER SERIES

\title{
REFERENCE POINT DEPENDENCE FOR SPECIFICATION BIAS FROM \\ QUALITY UPGRADING
}

Eric Hutton

John Whalley

Working Paper No. 4816

\section{NATIONAL BUREAU OF ECONOMIC RESEARCH \\ 1050 Massachusetts Avenue \\ Cambridge, MA 02138 \\ August 1994}

An earlier version of this paper was presented at the 4th Annual Waterloo Conference on Applied General Equilibrium Analysis, Waterloo, Ontario, October 27-29, 1993. We are grateful to conference participants for comments, and to Rob Feenstra for suggestions on an earlier draft. This paper is part of NBER's research program in International Trade and Investment. Any opinions expressed are those of the authors and not those of the National Bureau of Economic Research.

(C) 1994 by Eric Hutton and John Whalley. All rights reserved. Short sections of text, not to exceed two paragraphs, may be quoted without explicit permission provided that full credit, including (O) notice, is given to the source. 


\title{
REFERENCE POINT DEPENDENCE FOR SPECIFICATION BIAS FROM \\ QUALITY UPGRADING
}

\begin{abstract}
This paper argues that whether estimates of the welfare cost of natural or artificial trade barriers that do not discriminate by quality are subject to positive or negative specification bias when using models which do not explicitly recognize quality variation depends on the reference point used in counterfactual equilibrium analysis. We use numerical general equilibrium techniques to generate counter examples to the widely held view that (in the competitive case) incorporating quality upgrading will tend to reduce the welfare costs of quality invariant trade barriers. To do this, we use a trade-distorted equilibrium as the reference point, rather than free trade.
\end{abstract}

Eric Hutton

Center for the Study of

International Economic Relations

University of Western Ontario

London N6A 5C2

CANADA
John Whalley

Center for the Study of

International Economic Relations

University of Westem Ontario

London N6A 5C2

CANADA

and NBER 


\section{INTRODUCTION}

Specification bias is a term widely used by econometricians to describe situations where estimators will be systematically biased in one direction due to the use of an incorrect model (such as excluded variables). These issues, however, also arise in deterministic models. Here we examine how such biases operate in analyses of the effects of trade barriers (such as quotas) which do not discriminate by quality, arguing that the sign of the specification bias depends on the reference point used in counterfactual equilibrium analysis. We term this phenomenon reference point dependence.

The widely held belief is that including quality upgrading in models will (in the competitive case) tend to reduce the welfare costs of quality invariant artificial (quotas) or natural barriers to trade; i.e., models which exclude quality variation exhibit positive specification bias for predictions on the welfare costs of such barriers. This is because possible substitution into higher qualities is missing if quality variation is excluded from the analysis (Rodriquez (1979)), and adding additional substitution possibilities tends to mitigate the effects of such trade barriers and reduce their welfare costs.

We show how using a trade-distorted equilibrium as the base case (i.e., reference point) for counterfactual analysis, rather than a free trade reference point, reverses the bias. ${ }^{2}$ If the reference point is an equilibrium in the presence of the trade restriction, and if an observed quota premium value has been taken as given in calibration, then with more

\footnotetext{
2Das and Donnenfeld (1987), and Krishna (1987) have shown that even using free trade as a reference point, models which do not capture quality upgrading overstate welfare costs if a monopolistic market structure is introduced in the exporting country. Our analysis here, however, demonstrates reference point dependence for the conventional and widely held intuition developed for the competitive case.
} 
substitution possibilities rather than less (i.e., capturing quality substitution effects as against not), the gains from unwinding the restriction will be larger. ${ }^{3}$ The alternative intuition is that, viewed from a trade-distorted equilibrium, adding substitution possibilities raises measured welfare costs of such barriers since more substitution possibilities must have been distorted in generating the observed premium value associated with the trade restriction."

We also show that conventional results on the effects of quality upgrading on the relative price of higher to lower quality goods are subject to specification bias. These can be reversed by incorporating the common developing country feature that higher quality goods are produced mainly for export markets. The well-known proposition that quality upgrading raises the relative price of lower compared to higher quality goods in the quota-restricted market (Falvey (1979)) is thus dependent upon using as a reference point a small open pricetaking economy for whom world prices remain unchanged. In the case where the price-

\footnotetext{
${ }^{3}$ What we portray as the standard proposition on quality upgrading also stands in contrast to what one finds in the tax literature on the related issue of the comparison across models with differing levels of disaggregation. In this literature, the presumption is that increased disaggregation in models (such as between high and low-quality products) raises the measured cost of tax distortions, reflecting Harberger's t-square rule and the presence of increased variation in tax rates at more disaggregate level. Shoven and Whalley (1992), for instance, report added distortion costs of 30 percent when 2 sectors are disaggregated into 10 sectors in a U.S. capital tax model, with model comparisons made on an equal-tax yield basis.

'The empirical literature on quality upgrading does not discuss these issues, but instead seeks to measure the extent of the upgrading. Feenstra (1984) attributes 30 percent of the price rise for Japanese autos in the U.S. under the U.S. VER program in the 1970 s to quality upgrading. Bornstein and Feenstra (1987) similarly evaluate quality upgrading in steel; Aw and Roberts (1986, 1988) and Aw (1992) evaluate upgrading effects for Taiwanese and Korean footwear in the U.S. Anderson (1985) analyzes quality effects due to U.S. cheese import quotas, but estimates the extra cost of quotas that produce different ad valorem equivalents across different grades of cheese relative to an equivalent constant ad valorem set of trade restrictions; a different set of issues than those taken up here.
} 
taking assumption is dropped and where exporters produce high-quality products largely for the export market (which is typically the case) and domestic consumption is primarily of lowquality product, the conventional price effects attributed to quality upgrading can be reversed. 


\section{PREVIOUS DISCUSSION OF SPECIFICATION BIAS AND OUALITY UPGRADING}

Quality upgrading is the substitution of higher quality for lower quality products (or vice versa) in production or consumption, and is typically caused by natural or artificial barriers to trade that do not discriminate by quality. Examples are transport costs which result in proportionally more higher quality items being shipped between regions, such as between the Western and Eastern U.S.'; and apparel import quotas which make no quality distinction and hence cause quality subsitution, such as those administered in terms of number of items or square yardage allowed to be imported.

A central proposition in the literature is that the measured welfare costs of such trade restrictions are smaller in models which incorporate quality upgrading than in models which do not, since upgrading provides opportunities to substitute out of the restrictive effects of barriers; i.e., models which fail to capture quality variation show positive specification bias in their predictions as to the welfare costs of such barriers. Feenstra (1984), following Rodriquez (1979), shows this by representing quality upgrading as changes in the amount of services provided per physical unit of product consumed.

Thus if

$$
S=x Q
$$

\footnotetext{
'Alchian and Allen (1972) (and cited by Jones (1984)) suggest transportation barriers as the explanation for why proportionally more higher than lower quality apples are shipped between the westem and eastem states of the U.S. than consumed there.
} 
where $x$ denotes services per physical unit, and $Q$ denotes physical units, then $S$ denotes service inclusive units of the product, and the effects of tariffs and quotas on imports of $Q$ differ, since a lariff on the value of imports has no effect on $x$, while a quota increases $x$.

To analyze the effects of either including or excluding quality upgrading from analyses of the impacts of quotas which do not discriminate by quality, Feenstra (and Rodriquez) considers the simple case where there is no domestic production. With service units wholly imported, only demand side effects of the trade restrictions come into play. They consider the case of a VER with rents fully transferred by the importing to the exporting country, and use a partial equilibrium measure of the cost to the importing country of the trade restriction. Thus, given $S(p)$, a compensated demand function for service inclusive units, the cost to the importing country (capturing quality upgrade effects through induced changes in $x$ ) of introducing the trade restriction is

$$
\Delta p S^{v}+\frac{1}{2}(\Delta p \Delta s)
$$

where $\Delta p$ denotes the change in the price of services induced by the trade restriction, $S^{N}$ denotes the quantity of service inclusive units demanded in the presence of the trade restriction (i.e., $\Delta p S^{N}$ is the rent transfer abroad), and $\Delta s$ is the change in service demand. The term $\frac{1}{2} \Delta p \Delta s$ is the Harberger measure of welfare loss in the importing country, to which any rent transfers have to be added.

If quality upgrading were ignored in the analysis, and demands measured in physical not service units, $\Delta q$ (rather than $\Delta s$ ) denotes the quantity change, and $p x$ becomes the price 
per physical unit. Thus, in ignoring quality upgrading, the cost to the importing country of introducing the trade restriction is

$$
\Delta(p x) q^{N}+\frac{1}{2}(\Delta(p x) \Delta q)
$$

where $\Delta(p x)$ is the change in the price per physical unit, and $q^{N}$ is the physical quantity demanded in the presence of the trade barrier. The term $\Delta(p x) q^{N}$ is the measured rent transfer in this case, and $\Delta q$ is the change in physical quantity demanded.

Subtracting (2) from (3) yields a clear overestimate of the cost to the importing country of imposing the trade restriction, attributable to not taking into account quality upgrading: i.e.

$$
\frac{1}{2} \Delta x\left(p^{O} q^{N}+p^{N} q^{9}\right)
$$

where $\Delta r$ is the increase in service units per physical unit with the introduction of the quota (quality upgrading), and $p^{\circ}, q^{N}, q^{\circ}$, and $q^{N}$ are prices of service inclusive units and physical quantities before $(O)$ and after $(N)$ the introduction of the quota. All the terms in (4) are positive; hence ignoring quality upgrading leads to an overestimate of the costs of a quota which does not differentiate by quality.

A second proposition in the literature, due to Falvey (1979), concerns the pricing effects of quality upgrading. This can be shown in the simple case where there are two imports, one high and one low quality, with, for simplicity, constant marginal cost of production $c_{l}$ and $c_{2}$ for each in the exporting country. If good 1 is of higher quality, and if units of products are measured in comparable physical terms (say, tons), then $c_{t}>c_{2}$. If a 
tariff applies at rate $t$ to both products, then consumer prices in the importing country increase proportionately; i.e.,

$$
p_{1}^{N}=(1+t) c_{1} ; \quad ; \quad p_{2}^{N}=(1+t) c_{2}
$$

and relative prices remain unaffected by the tariff. If, however, a physical quota (of the VER type) is used by the importing country, exporters equate per-unit profits across the products shipped; i.e., $p_{1}^{N}-c_{1}=p_{2}^{N}-c_{2}$, where $p_{1}^{N}$ and $p_{2}^{N}$ are again the consumer prices for goods $l$ and 2 after the quota is introduced. Since $c_{1}>c_{2}, p_{1}^{N / p} p_{2}^{N}<c_{1} / c_{2}$; i.e., the relative price for the higher quality good falls. 
8

\section{SHOWING REFERENCE POINT DEPENDENCE FOR OUALITY UPGRADING SPECIFICATION BIAS}

To show refesence point dependence of the specification bias which can arise when evaluating the welfare effects of quality invariant trade barriers, we use the same applied general equilibrium methodology as set out in Shoven and Whalley (1992) of calibration of models to a base-case equilibrium data set followed by counterfactual equilibrium analysis for changes in policy or other parameter values. We perform such analyses for an arbitrarily chosen numerical model formulation, and for different model variants (with and without quality upgrading), and for different reference points (free trade or trade-distorted equilibria). The results from these compulations confirm conventional wisdom using free trade as a reference point, and are opposite to conventional wisdom using a trade-distorted equilibrium as the reference point, showing that the specification biases involved is dependent on the reference point chosen.

The conventional approach in numerical simulation work, including using the applied general equilibrium models discussed in Shoven and Whalley is to calibrate models to observed barrier-ridden equilibria and compute free trade equilibria as counterfactuals. Thus, in evaluating the specification bias which can arise from not incorporating quality variation in analyses of trade barrier impacts, proceeding in the opposite direction from theoretical analyses (i.e., beginning from an observed barrier-ridden equilibrium) seems the natural way to proceed, but is at variance with procedures held in pure theory which on grounds of tractibility begin from free trade. But, if model calibration is made to an observed quota premium value (modelling practice being to calibrate to observables), using 
models incorporating quality upgrade possibilities increases (not reduces) the welfare cost of trade restrictions because a given premium value for a quota restriction generated by a model with more substitution possibilities implies high distorting costs.

The models that we use to investigate these examples of specification bias are deliberately kept simple since our purpose is to show clear counter examples to conventional wisdom, rather than to use a higher dimensional, more empirically based structure, but with a less transparent formulation. In each model, there are two countries (North and South) and either three goods (high quality, low quality, and other goods), or two goods (composite, and other goods) depending upon whether or not quality variation is incorporated. For simplicity, production in each country is specified by a transformation frontier rather than through explicit production functions. We use nested CET (Constant Elasticity of Transformation) functions in each country, with GDP being defined over the composite good and other goods. In the model with quality variation, the composite covers high and lowquality components in a second level. Preferences in the two regions reflect the same structure, with CES (Constant Elasticity of Substitution) utility functions being defined over other goods and the composite, which, in the model with quality variation, is an aggregation over high and low-quality components.

In both models, the North imposes export quotas of the VER form upon all but the other good, with quota rents transferred to the Southem exporter. Quotas are expressed in terms of physical units; adding across high and low-quality imports in the model without quality variation. Since prices of goods are on a physical (not hedonic) unit basis, prices of high-quality goods are above those of low-quality goods in the base-case data, reflecting the 
quality variation. Equilibrium in the no-quota case is characterized by global market clearing for all goods. In the presence of quotas, there is a further market clearing condition within the country market for quota-restricted goods, as well as for the quota itself. In the model, equilibrium prices for quota-restricted items in the North and South are endogenously determined, along with world prices for other goods and quota premia.

Using the same approach, the relative price effects across lower and higher quality products generated on the demand side in importing countries, and stressed in existing literature, can also be analyzed alongside the production side effects in exporting countries, which are not discussed in the literature. Indeed, if, as is common in developing countries, high-quality products are produced largely for export markets with low-quality products produced largely for domestic markets, the relative price effects from the production side can dominate the demand side effects stressed in the literature.

Details of the procedures we follow in using these models to show the reference point dependence for specification bias we claim above are set out in Table 1. We first construct a simple benchmark equilibrium data set incorporating quality substitution in the presence of binding import quotas, covering trade, production and consumption. Using this data set, we then construct a further base-case equilibrium data set without quality substitution, identical in aggregated value form to the model with quality upgrading. This enables us to calibrate comparable models (with and without quality variation) in the presence of barriers using each data set; i.e., with a constant quota premia across models with and without quality upgrading (boxes [1] and [2] in Table 1). 
Table 1

Experimental Procedures Used in Demonstrating Reference Point Deperdence or Quality Uparadine Specilication bias

\section{[1]}

Construction of initial Benchmark

Equilibrium Data Set with barriers, with quality variation
[2]

Construction of Comparable Aggregated Benchmark Data Set with no quality variation, with comparable (composite) quota premium value

\section{[3]}

Model Calibration, Computation of

Free Trade Equilibrium as

Counterfactual

\section{[4]}

Model Calibration, Computation of Free Trade Equilibrium as

Counterfactual

Estimates of Welfare Gain from Elimin-

ating Trade Restrictions calculated for

each model and estimates compared across models

[6]

Computed Free Trade Equilibrium taken as Altemative Benchmark Equilibrium in Reverse Calibration

\section{[8]}

Model Calibration, Computation of Quota-Restricted Equilibrium as counterfactual
[7]

Aggregated free trade equilibrium with no quality variation constructed as additional benchmark equilibrium data set

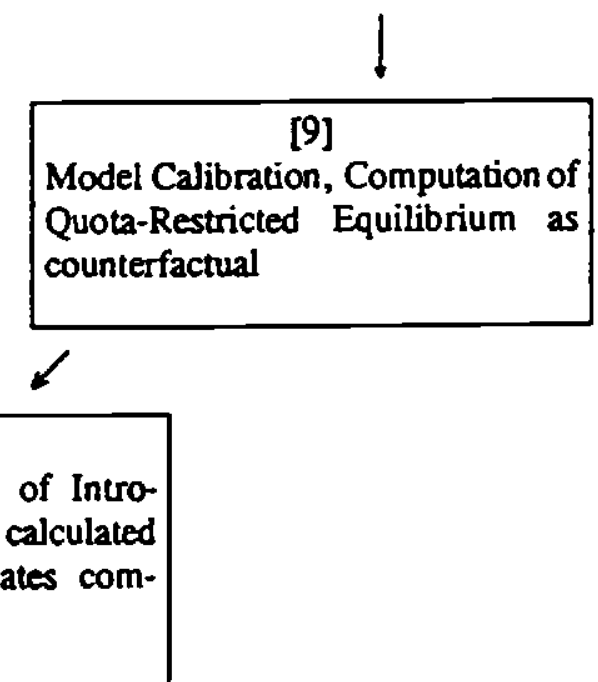


Counterfactual free trade equilibria are then computed for each of the models, with and without quality variation (boxes [3] and [4] in Table 1). We then compare across models to see which yields higher estimates of welfare gains from eliminating the quota trade restrictions (box [5] in Table 1).

The computed free trade equilibria are then used to perform alternative calibrations to free trade data sets (boxes [6] and [7]) for models with and without quality upgrading, and we then compute counterfactual equilibria in the presence of quota restrictions (boxes [8] and [9]). Once again, we compare across models to see which yields the higher estimates of welfare costs from imposing quota restrictions (box [10]). Evaluating the two pairwise model comparisons (box [5] and box [10]), we assess whether, as suggested above, the outcome depends upon the reference point (i.e., beginning from barrier-ridden equilibria (boxes [1] and [2]), or from free trade equilibria (boxes [6] and [7]). 


\section{NUMERICAL RESULTS FROM MODEL CALCULATIONS}

We have used the procedures set out in Table 1 to show how the specification bias involved in excluding quality upgrading from analyses of the measured welfare costs of trade restrictions depends on the reference point used. In Tables 2 and 3, we report numerical calculations which show that the impact of incorporating quality upgrading on the welfare effects of quotas depends upon whether the initial data set for calibration is a trade-distorted equilibrium or a free-trade equilibrium.

The first set of experiments in Table 2 begins from a trade-distorted equilibrium, with the counterfactual in both cases (with and without quality variation) being a move to free trade. Observations for each of two benchmark equilibria data sets are reported in value terms in the upper panels (A.I and B.1), along with quantity observations. From the freetrade counterfactual equilibria, the effects of removing quota restrictions can be seen in either case (A.2 and B.2). With or without quality variation, the North benefits both from the domestic consumption gains from eliminating the quota and the saving on transfer of quota rents, while the South loses because of the loss of the rent transfers. In equilibrium, the domestic prices of high and low quality goods are the same across the two countries.

In using the model with quality variation, the world welfare gain calculated as the sum of Hicksian equivalent variations across the two countries is 3.51 . In contrast, in the case without quality variation, the sum of compensating variations is 2.89 . Thus, using a trade-distorted equilibrium as the base case, the counterfactual equilibrium generated from a model without quality variation yields a smaller welfare gain from the elimination of the 
TABLLE 3

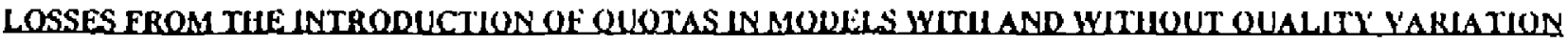

A. Model wlth Quallty Yadatlon

1. Benchmark Equitlbrium Data (free trade) North

South

Good

Hogh Low Other Quentidies

\begin{tabular}{|c|c|c|c|}
\hline & $\begin{array}{l}\text { Hegt } \\
\text { Ounentitie }\end{array}$ & Lom & Other \\
\hline Production & $\$ 1.1$ & 171.4 & 2350.6 \\
\hline Consumption & {$[00] .3$} & 10324 & 1904.9 \\
\hline Na Tode & .100 .3 & .161 .4 & 314.1 \\
\hline
\end{tabular}

$$
\text { Domadc Prias: }
$$

$$
\begin{array}{|r|r|r|}
\hline 2.09 & 1.03 & 1.00 \\
\hline
\end{array}
$$

\begin{tabular}{|c|c|c|c|c|c|c|}
\hline & Iive & $\mathrm{Nat}$ & $\operatorname{sen}$ & & & \\
\hline Production & 1071.3 & \pm 4 & D0\$6 & 425.3 & 2000,0 & 1644.9 \\
\hline Conemption & $\sin 2$ & 1004.9 & Ipat.s & 300.7 & 19216 & 20326 \\
\hline Nat Trade &. minal & -1604 & 340.1 & 271.6 & 106.4 & .368 .1 \\
\hline
\end{tabular}

Yelue Obearvedonia (e domeadc prioed)

\section{Counterfactual Equilbrium (wth bartiers)}

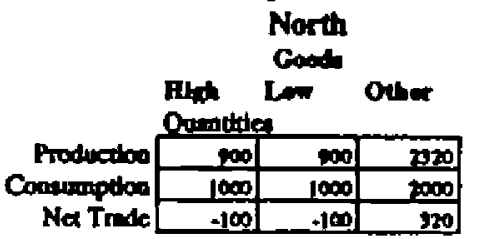

South

Gonds
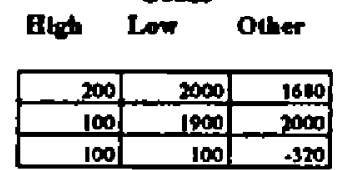

$$
\text { Donestic Prios }
$$

$$
\text { 21 } 1.11 \text { il }
$$

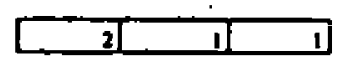

B. Model with no Quality Vadation

1. Benchmark Equiltbrium Data (free trade)

North

Goode

Compante Other

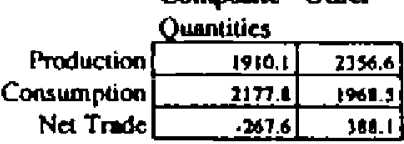

Domeste Prices

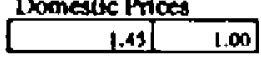
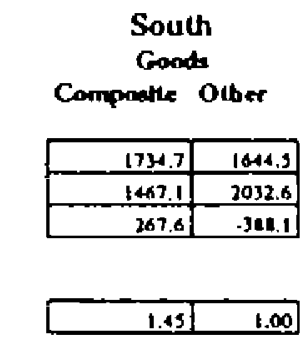

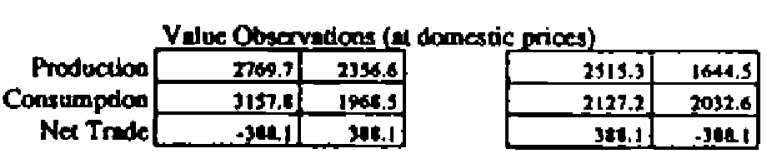

2. Countertactual Equilbrium (wth barters)

North South

Good.

Compates Other

$$
\text { Good }
$$

Compontte Other

\begin{tabular}{|c|c|c|c|c|}
\hline \multicolumn{5}{|c|}{ Youes Observation of domesdic of } \\
\hline Production & 2913.3 & 2309.2 & 234.8 & 1099.6 \\
\hline Consumption & 3213,3 & 2009.3 & 2000.6 & 1909.5 \\
\hline Nex Trude &.$\$ 000$ & Fm,9 & 27.2 & .799 .9 \\
\hline
\end{tabular}

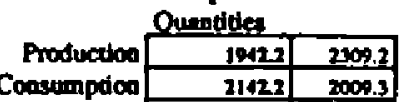

\begin{tabular}{rr|r|} 
Consumpdico & 2142.2 & 2000.3 \\
\hline Nat Trade & 299.9 \\
\hline
\end{tabular}

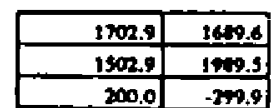

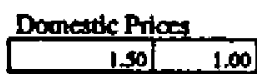

\begin{tabular}{l|l|}
1.39 & 1.00 \\
\hline
\end{tabular}

3. Welfare Changes Acros Equilibria

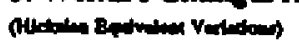

$\begin{array}{lllll}\text { NORTH } & -11.46 & \text { SOUTH } & 7.99 & \text { SUM }\end{array}$


quota trade restriction, demonstrating the negative specification bias that we outline above. This result is not only truefor the arithmetic (global) sum of the Hicksian equivalent variations, but also for the separate Hicksian equivalent variations calculated for the North and the South.

Table 3 reports results for counterfactual equilibrium calculations executed in reverse fashion; moving instead from a free-trade base case to a trade-distorted equilibrium. In this case, the first benchmark equilibrium data set (A.1.) is the same as the counterfactual free trade equilibrium data set (A.2.) reported in Table 2. This generates identical model parameters to the earlier case through calibration. The counterfactual is the introduction of a quota which leads to the same quota premia value as in the base case (data set (A.1)) in Table 2. The second equilibrium data set (B.1.) reported in Table 3 is generated by aggregating across the quality variations in Table 2. Results are again generated as welfare comparisons across equilibria and across models, but unlike in Table 2 , the welfare loss from introducing the trade restriction is higher in the no-quality variation model than in the withquality variation model. Results in Table 3 thus show that introducing quality upgrading into model-based analyses reduces the cost of restrictions (as per received wisdom), since further substitution out of the restricting effects of the quota is possible, while results in Table 2 suggest the opposite.

The difference relative to Table 2 is that in Table 3 the quota premium values differ across the two counterfactual equilibria produced by aggregated and disaggregated models because calibration is no longer taking place to a given base-case quota premium value, but instead to a free-trade equilibria in which the quota premium value is zero. 
Results in Table 2 also shed light on the results we mention above as to the effects of quality upgrading on the relative price of higher and lower quality goods. They show how these results can be reversed under a formulation which captures global price effects from supply side changes in exporting countries. Table $2(\mathrm{~A})$ has been constructed in such a way that the exporting country produces a higher proportion of high quality goods for export relative to domestic consumption than is true of low-quality goods. ${ }^{6}$ Incorporating this feature, we obtain the result that, in a move from a barrier-ridden equilibrium to free trade, the proportional increase in the price of high-quality goods exceeds the proportional increase in the price of low-quality goods.

This can be seen in Table 2 (Panel A), where the world price (as reflected in the price received by the exporting country) for high-quality goods increases from 2 to 2.09 , a proportional increase of 1.045; whereas the proportional increase in the low-quality good is only 1.03. As noted above, this is opposite to the earlier Falvey result for the small open economy case because this analysis captures production and hence supply side effects in the two countries and, in this case, these are strong enough to reverse the result. We also note above that for developing countries, production of high-quality product, especially for export, is commonly undertaken, and so this may be a more typical case than that considered in the literature. Also in such cases it is clearly misleading to treat large importing countries as price-takers.

\footnotetext{
${ }^{\circ} \mathrm{We}$ note in passing that the quality upgrading welfare results stressed earlier are not dependent on this feature of the example; while it has been incorporated so as to yield these pricing results, we have also performed experiments yielding similar welfare results to those above, but without the different relative price effects from conventional analysis by removing this feature.
} 


\section{SUMMARY AND CONCLUSIONS}

This paper uses numerical simulation methods to show how the reference point chosen (free trade or a trade-distorted equilibrium) is critical when evaluating the specification biases that may be involved when analyzing the effects of trade restrictions (such as quotas) which do not discriminate on the basis of quality. Specifically, and in contrast to conventional wisdom, we show that whether or not explicitly including quality upgrading increases or reduces the welfare costs of such trade restrictions is ambiguous as to sign, even in the competitive case. Conventional wisdom is based on the intuition that incorporating added substitution margins (quality variation) will reduce the cost of the restriction. This takes free trade as the reference point. We argue that if the reference point is instead a trade-distorted equilibrium, adding substitution possibilities raises rather than lowers the costs of such restrictions, as increasingly severe distortions must be implied to generate the same reference point equilibrium data. We also indicate that this is the intuition suggested by related empirical work in public finance on the cost of distortions, which typically begins from observed (or with tax) equilibria.

We finally note that effects on production as well as consumption in exporting countries can also reverse the traditional pricing result that quality upgrading tends to lower the relative price of high to low-quality goods. Extensions of our analysis to more complex cases involving multiple countries and qualities are possible. We have not undertaken them since our intent is to make our main methodological point, rather than undertake more realistic and elaborate calculations which are inevitably less transparent. 


\section{REFERENCES}

Alchian, A. and W. Allen (1972). Universiry Economics, 3rd Edition. Wadsworth, Belmont, California.

Anderson, J.E. (1985). "The Relative Inefficiency of Quotas." American Economic Review 75, No.1, pp. 178-190.

Aw, B.Y. and M.J. Roberts (1986). "Measuring Quality Changes in Quota Constrained Import Markets: The Case of U.S. Footwear." Joumal of International Economics $21, \mathrm{pp} .45-60$.

Aw, B.Y. and M.J. Roberts (1988). "Price and Quality Comparisons for U.S. Footwear Imports: An Application of Multilateral Index Numbers" in Robert C. Feenstra (ed.), Empirical Merhods for Intemarionol Trade, MIT Press, Cambridge, Massachusetts, pp. 257-275.

Aw, B.Y. (1992). "An Empirical Model of Markups in a Quality-Differentiated Export Market." Journal of Internationol Economics, Vol.33, No.3/4 (November), pp.327344.

Boorstein, R. and R.C. Feenstra (1987). "Quality Upgrading and Its Welfare Costs in US Steel Imports, 1969-1974." Mimeo, Federal Trade Commission and the University of California.

Das, S.P. and S. Donnenfeld (1987). "Trade Policy and Its Impact on Quality of Imports. A Welfare Analysis." Joumal of Intemational Economics 23 (1987), pp.77-95.

Falvey, Rodney E. (1979). "The Composition of Trade Within Import-Restricted Product Categories." Joumal of Political Economy 87, No.5 (October), pp.1105-14.

Feenstra, Robert C. (1984). "Voluntary Export Restraint in U.S. Autos, 1980-81: Quality, Employment, and Welfare Effects" in Robert E. Baldwin and Anne O. Krueger (eds.), The Structure and Evolution of Recent U.S. Trade Policy. NBER, The University of Chicago Press, Chicago and London, U.K.

Feenstra, Robert C. (1992). "How Costly is Protectionism." Joumal of Economic Perspecrives, Vol.6, No.3 (Summer), pp.159-178.

Jones, Ronald W. (1984). Comment on "Voluntary Export Restraint in U.S. Autos, 198081: Quality, Employment, and Welfare Effects" by Robert C. Feenstra in Robert E. Baldwin and Anne O. Krueger (eds.), The Structure and Evolurion of Recent U.S. Trade Policy. NBER, The University of Chicago Press, Chicago and London, U.K. 
Krishna, K. (1987). "Tariffs Versus Quotas with Endogenous Quality." Joumal of Intemarional Economics 23, pp.97-122.

Rodriguez, Carlos Alfredo (1979). "The Quality of Imports and the Differential Welfare Effects of Tariffs, Quotas, and Quality Controls as Protective Devices." Canadian Joumal of Economics 12, Pp.439-49.

Shoven, J. and J. Whalley (1992). Applying General Equilibrium. Cambridge University Press.

Trela, I. and J. Whalley (1990). "Global Effects of Developed Country Trade Restrictions on Textiles and Apparel." The Economic Joumal, Vol.100, No.403, December, Pp.1190-1205. 